\title{
Application of FTIR fingerprints coupled with chemometric for comparison of stingless bee propolis from different extraction methods
}

\author{
Nur Basyirah Md Zin a, Azierah Azemin ${ }^{\mathrm{b}}$, Muhammad Muslim Mohd Rodi a, Zalilawati Mat Rashid a, \\ Khamsah Suryati Mohd a, \\ ${ }^{a}$ Faculty of Bioresources and Food Industry, Universiti Sultan Zainal Abidin, Besut Campus, 22200 Besut, Terengganu, Malaysia \\ ${ }^{b}$ East Coast Environment Research Institute (ESERI), Universiti Sultan Zainal Abidin, Gong Badak Campus, 21300 Kuala Nerus, Terengganu, \\ Malaysia \\ * Corresponding author: khamsahmohd@gmail.com
}

\section{Article history}

Received 28 December 2018

Revised 22 February 2019

Accepted 4 April 2019

Published Online 15 May 2019

\begin{abstract}
Propolis is a mixture of resin collected by the bees to build their hive. These mixtures contain natural remedy and used to treat variety of health-related problems. Unlike honeybee propolis, the study of stingless bee propolis still lacking. The important part of propolis study is the optimization of extraction procedures. The aim for this study is to employ chemometrics on FTIR data in order to discriminate the chemical fingerprinting of Malaysian stingless bee, Heterotrigona itama propolis yielded from different extraction methods, which were maceration, sonication and soxhlet. The chemical fingerprinting was obtained through Fourier Transform Infrared (FTIR). Principle component analysis (PCA) and hierarchical cluster analysis (HCA) were applied as pattern recognition methods for FTIR spectra. PCA of FTIR data for different extraction methods of stingless bee's propolis revealed that variability of PC1 and PC2 is $84.76 \%$. PCA's variation in propolis by different extraction methods was classified based on specific functional groups arisen from the peaks. The FTIR fingerprinting of HCA of stingless bee's propolis were distributed into three clusters based on percentages of ethanol, intensity of peaks and different fingerprint region. FTIR coupled with chemometric analysis showed classification of different extraction methods of propolis from PCA and HCA based on vibration of functional groups presence in the samples. Taken together, these results showed that different extraction methods play important role in detaining of chemical in propolis of stingless bee.
\end{abstract}

Keywords: Propolis, stingless bee, FTIR, PCA, HCA

(C) 2019 Penerbit UTM Press. All rights reserved

\section{INTRODUCTION}

Heterotrigna itama is a stingless bee from Apidae family. H.itama is one of the popular stingless bee among beekeepers in Malaysia and acts as pollinators to flowering plants. Stingless bee produces honey, propolis and bee bread in their hive. To date, there are more than 300 of chemical compounds have been identified from various honeybee propolis samples, including phenolic acid and their ester, flavonoid, amino acids, sugars or micro- and macroelements (Magdalena et al., 2015). Propolis is a resinous product that collected from various plants by stingless bees and mixed with their beeswax and salivary enzymes, $\beta$-glucosidase (Ricardo et al., 2015). Propolis has been used in hive as building materials as well as defensives substances from insects or microorganism (Bankova et al., 2014). The composition of propolis is depended on its botanical sources and geographical origin (Bogdanov et al., 2015) and also depended on season and vegetation (Araújo et al., 2016). Nowadays, propolis is still used in folk medicine, but becoming popular in healthy foods and drinks or in natural cosmetics and therapeutic. Apparently, there are some factors that affect the amount of chemical composition and biological activity in propolis, which are extraction methods (Niken et al., 2014) and solvents used for extraction (Prashant et al., 2011). At the moment, there are many extraction methods such as maceration (Irene et al., 2012), sonication (Khotai \& Jayanthi, 2015), soxhlet (Baldonaso et al., 2015), microwave (Ming et al., 2009) and reflux (Irene et al., 2012) that have been emphasized in order to obtain optimum extraction yield and higher chemical constituents. Generally, several methods have been developed in order to determine chemical composition in propolis such as UltraViolet- Visible (UV-Vis) (Renata et al., 2016), High Performance Thin Layer Chromatography (HPTLC) (Petar et al., 2014) and Gas Cromatography Mass Spectrometry (GC-MS) (Milena et al., 2017). In this study, maceration, sonication and soxhlet methods were used as extraction methods and FTIR was employed in determination of chemical fingerprint. Maceration is simple extraction method whereby the samples were soaked in a closed container and left in room temperature for a period of time (Azwanida, 2015). On the other hand, sonication works by cavitation energy that created the bubbles to release chemical compound in the samples (Khotai \& Jayanthi, 2015). Soxhlet is condensation and heating method to evaporate the solvent and concentrate the samples (Khacha-ananda et al., 2013). Fourier transform infrared spectroscopy (FTIR) is one of the simple 
and rapid tools to determine the functional group in a sample. This instrument produces spectrum occurring between $4000 \mathrm{~cm}^{-1}$ to 400 $\mathrm{cm}^{-1}$ by molecular vibration which are stretching and bending. Typically, the stretching mode has higher energy compared to bending mode. FTIR consists thousands of data sets and overlapping data that cannot be varied by human vision. Thus, chemometric tool is important to classify and discriminate the samples into their factor of interest. Chemometric is a tool that combines both mathematical and statistical methods in oder to get optimum results based on chemical measurement obtained (Rohman \& Salmah, 2018). The main purpose of chemometric is to investigate dominant modes of variation in data set by discrimination and classification using unsupervised Principal Component Analysis (PCA) and Hierarchical Cluster Analysis (HCA). (Rohman \& Salmah, 2018). This study was aimed to employ chemometric analysis on FTIR data in order to compare the chemical fingerprints of Malaysian stingless bee, Heterotrigona itama propolis yielded from different extraction methods, which were maceration, sonication and soxhlet.

\section{EXPERIMENTAL}

\section{Materials}

All the chemicals and reagents used in this experiment were analytical grade. Ethanol was purchased from Merck Sdn. Bhd, Selangor, Malaysia.

\section{Sample collection}

Propolis of Heterotrigna itama was collected from apiary of Universiti Sultan Zainal Abidin, Besut Campus. The samples were ground into powder and kept in $-80^{\circ} \mathrm{C}$ for futher analysis.

\section{Maceration extraction}

In brief, $18 \mathrm{~g}$ of powdered propolis were extracted with $60 \mathrm{~mL}$ of $70 \%$ and $95 \%$ ethanol for $1,3,5$ and 7 days. The ethanolic extracts were filtered using Whatman \#41 and concentrated using rotary evaporator (Heidolph Instruments $\mathrm{GmbH} 5$ \& Co. KG, German) under vacuum pressure at $45^{\circ} \mathrm{C}$. The extracted propolis for maceration were labelled as E70M-1 (Ethanol 70\%-Maceration-1 day), E70M-3 (Ethanol 70\%-Maceration-3 days), E70M-5 (Ethanol 70\%Maceration-5 days), E70M-7 (Ethanol 70\%-Maceration-7 days), E95M-1 (Ethanol 95\%-Maceration-1 day), E95M-3 (Ethanol 95\%Maceration-3 days), E95M-5 ( Ethanol 95\%-Maceration-5 days) and E95M-7 (Ethanol 95\%-Maceration-7 days).

\section{Sonication extraction}

Approximately, $18 \mathrm{~g}$ of powdered propolis was extracted in 60 $\mathrm{mL}$ of $70 \%$ and $95 \%$ ethanol for $10,30,60$ and 120 minutes at $37^{\circ} \mathrm{C}$ in sonicator bath (Jeio Tech UC-10). The ethanolic extracts were filtered using Whatman \#41 and concentrated using rotary evaporator (Heidolph Instruments GmbH 5 \& Co. KG, German) under vacuum pressure at $45^{\circ} \mathrm{C}$. The crude propolis for sonication were labelled as E70S-10 (Ethanol 70\%-Sonication-10 minutes), E70S-30 (Ethanol 70\%-Sonication-30 minutes), E70S-60 (Ethanol 70\%-Sonication-60 minutes), E70S-120 (Ethanol 70\%- Sonication-120 minutes), E95S-10 (Ethanol 95\%-Sonication-10 minutes), E95S-30 (Ethanol 95\%Sonication-30 minutes), E95S-60 (Ethanol 95\%-Sonication-60 minutes) and E95S-120 (Ethanol 95\%-Sonication-120 minutes).

\section{Soxhlet extraction}

Approximately $5 \mathrm{~g}$ of propolis was extracted in $150 \mathrm{~mL}$ of $70 \%$ and $95 \%$ ethanol for 2, 4, 6 and 8 hours by soxhlet extractor (Soxhlet extractor M-Top, Korean South). The ethanolic extracts were filtered using Whatman \#41 and concentrated using rotary evaporator (Heidolph Instruments GmbH 5 \& Co. KG, German) under vacuum pressure at $45^{\circ} \mathrm{C}$. The crude propolis for soxhlet were labelled as E70SH-2 (70\% Ethanol-Soxhlet-2 hours), E70SH-4 (70\% EthanolSoxhlet-4 hours), E70SH-6(70\% Ethanol-Soxhlet-6 hours), E70SH-8 (70\% Ethanol- Soxhlet-8 hours), E95SH-2 (95\% Ethanol-Soxhlet-2 hours), E95SH-4 (95\% Ethanol-Soxhlet-4 hours), E95SH-6 (95\%
Ethanol-Soxhlet-6 hours), and E95SH-8 (95\% Ethanol-Soxhlet-8 hours).

\section{The FTIR analysis of propolis extracts}

The FTIR spectra of propolis extract samples were analyzed using IRPrestige-21 Shimadzu Fourier Transform Infrared Spectrophotometer (Tokyo, Japan) according to method by Azemin et al. (2017). FTIR spectrometer was coupled with DLATGS (Deuterated Triglycine Sulfate doped with L-Alanine) and equipped with air-cooled ceramic infrared light source. Propolis extracts were recorded at the middle-IR range $4000-600 \mathrm{~cm}^{-1}$ at resolution $4 \mathrm{~cm}^{-1}$ by co-adding 16 scans. After every scans, the background spectrum was taken. The sticky propolis extract was smeared directly on the diamond prism. The diamond prism was carefully cleaned by rubbing the soft tissue (Kimtech Science, Kimwipes) with 70\% ethanol before the next samples were applied. The measurement of FTIR data set was baseline correction to minimize the difference between the spectra during baseline shift, normalized and smoothed to reduce noise in spectral data.using Shimadzu IRsolution Version 1.40 (Shimadzu Corporation) software.

\section{Pre-processing data}

The FTIR data sets $(1763 \times 24$ datasets $)$ from Shimadzu IRsolution software for FTIR data from normalized and smoothing were saved in file txt and copied manually to Microsoft Excel as two data sets (rows: samples; and columns: wavenumber) for extracting their numerical values from spectra files. Then, the noise range 599$400 \mathrm{~cm}^{-1}$ was cut off and the data was aligned in rows for samples and column for wavenumber. All FTIR samples were subjected to unsupervised pattern recognition by Principal Component Analysis (PCA) and Hieararchical Cluster Analysis (HCA) which conducted by XLSTAT Pro 2014 (Addinsoft, Paris, France), an add-in software program for Microsoft Excel 2010.

\section{Principlal Component Analysis (PCA)}

PCA is a mathematical procedure which used to reduce the dimensionality of the large data sets to a small sets by retaining the variability of the data sets in principal component (PCs) (Jollife, 2002). Usually, the most two PCs namely as PC1 and PC2 were used because these two PCs contributed to higher variance in a given data sets. If the factors were difficult to interpret after the component have been analysed, the varimax rotation was applied. Varimax rotation is an orthogonal rotation that used to facilitate the interpretation by reducing the variability of the principle component as known as varimax factor (VFs). (Herve \& Lynne, 2010). The varimax rotation was applied on the PCs when eigenvalue was more than 1 . Eigenvalues would measure the total variation in the total samples in each PCs. The higher the total variation, the more the observation would contribute to that PCs.

\section{Hierarchical Cluster Analysis (HCA)}

The goal of using HCA was to find the best grouping observation which was the cluster dissimilarity to each other and within cluster that similar to each other (Ami et al., 2012). The similarity and dissimilarity were called distance function such as Euclidean distance. (Mohamad-Asri et al., 2018). HCA was performed using the single linkage technique to link the clusters and Euclidean distance. The Hieararchical algorithm was divided into two; agglomerative or divisive. The agglomerative method is many-to-one method, in which the clustering is placed in different clusters and each step of a cluster of observations is merged into another cluster. Meanwhile, the divisive method is one-to-many method, in which is one single cluster is contained all observations and divided to two subclusters. The dissimilarities between the samples increase were observed by the higher relative distance between the samples shown in dendogram (Azemin et al., 2017). 


\section{RESULTS AND DISCUSSION}

Three extraction methods; maceration, sonication and soxhlet were employed in order to obtain bioactive extracts. Maceration is traditional method of extraction for natural product material Eventhough it is effective, but this method is a time consuming, which required 2-10 days to get higher yield. In comparison, modern method such as sonication and soxhlet extraction have been developed for fast and efficient extraction method. Sonication required short time extraction and lower temperature to extract and thus, it can avoid thermal damages and preserve the structural and molecular properties of propolis (Tian et al., 2013). On the other hand, soxhlet required small amount of solvent and can produce higher extraction yield because of the continuous process during extraction. Extraction method is important in order to produce higher extraction yield besides to extract bioactive compound in propolis.

\section{Fingerprinting of propolis by Fourier Transform Infrared Spectroscopy (FTIR) analysis}

FTIR is a rapid, efficient and accurate analytical method that measured the vibrational of functional group in a wavelength middleIR range $4000-600 \mathrm{~cm}^{-1}$ based on bending and streching vibrations. The typical FTIR spectra for propolis extracts of different extraction methods were shown in Fig. 1. From Fig. 1, the patterns of FTIR peaks were appeared similar but mostly occurred in different intensities. FTIR of stingless bee's propolis by different extraction methods showed complex chemical composition. It could be observed that peak at $3550-3200 \mathrm{~cm}^{-1}$ was assigned to intermolecular hydrogen bonding (O-H stretching vibrations). This peak was presence in all extraction methods but with different intensities. The intensity of this peak range was found to be broad and strong peak for $70 \%$ ethanol extracts as compared to $95 \%$ ethanol extracts in all extraction methods. The peak at $2968 \mathrm{~cm}^{-1}$ and $2855 \mathrm{~cm}^{-1}$ were attributed to asymmetrical stretching of methyl group $\left(\mathrm{V}_{\mathrm{as}} \mathrm{CH}_{3}\right)$ and symmetrical stretching vibration of methylene group $\left(\mathrm{V}_{\mathrm{S}} \mathrm{CH}_{2}\right)$ respectively. These peaks were presence in maceration (E70M-1, E70M-3, E70M-5 and E70M-7) and in sonication (E70S-30, E70S-60 and E70S-120). While the $2923 \mathrm{~cm}^{-1}$ peak was due to symmetrical stretching of $\left(\mathrm{V}_{\mathrm{s}} \mathrm{CH}_{3}\right)$ of methyl group presence in all extraction methods.

In the range of $1730-1726 \mathrm{~cm}^{-1}$, peaks could be seen probably related to $\mathrm{C}=\mathrm{O}$ stretching vibrations of aliphatic aldehydes was found in all extraction methods. However, 95\% ethanol produced intense peak as compared to $75 \%$ ethanol. Furthermore, peak at $1715-1711$ $\mathrm{cm}^{-1}$ (normal $\mathrm{C}=\mathrm{O}$ streching vibration of saturated aliphatic ketone) was presence in maceration methods (all samples), sonication (all samples in 95\% ethanol and E70S-30, E70S-60 and E70S-120) and soxhlet $\left(95 \%\right.$ ethanol). The peaks at $1697-1692 \mathrm{~cm}^{-1}(\mathrm{C}=\mathrm{O}$ stretching vibration of unsaturated and aryl conjugated carboxylic acid), 1666$1665 \mathrm{~cm}^{-1}(\mathrm{C}=\mathrm{C}$ stretching vibration of disubstituted trans alkene, triand tetraalkyl-substituted alkenes $)$ and $1659 \mathrm{~cm}^{-1} \quad(\mathrm{C}=\mathrm{C}$ streching vibration of cis- alkene) were found in $70 \%$ ethanol by soxhlet and 70S-10.

Peak at range $1645-1641 \mathrm{~cm}^{-1}$ was presence in all extraction methods that contributed to $\mathrm{C}=\mathrm{C}$ stretching vibration of vinyl group. Besides that, peak at range $1636-1632 \mathrm{~cm}^{-1}$ was attributed to $\mathrm{C}=\mathrm{C}$ stretching vibration and only found in maceration (E70M-1, E70M-3, E70M-5 and E70M-7) and in sonication (E70S-30, E70S-60 and E70S-120 ). On the other hand, conjugated $\mathrm{C}=\mathrm{C}$ streching vibration was found in all extraction methods approximately at $1600 \mathrm{~cm}^{-1}$. The peaks at $1587-1582 \mathrm{~cm}^{-1}, 1574-1572 \mathrm{~cm}^{-1}, 1564 \mathrm{~cm}^{-1}, 1557-1553 \mathrm{~cm}^{-1}$ and $1549-1547 \mathrm{~cm}^{-1}$ were assigned as $\mathrm{C}=\mathrm{C}$ streching vibration. The peak in the ranges of $1517-1515 \mathrm{~cm}^{-1}$ was assigned as $\mathrm{C}=\mathrm{C}-\mathrm{C}$ aromatic streching and occurred in all extraction methods. was only stable until 6 hours extraction. On the other hand, there were two distinct peaks occuring in all extraction methods approximately in the range 1439-1433 $\mathrm{cm}^{-1}$ and $1375 \mathrm{~cm}^{-1}$, which attributed to asymmetrical bending vibration $\left(\delta_{\mathrm{as}} \mathrm{CH}_{3}\right)$ and symmetrical bending vibration $\left(\delta_{\mathrm{s}} \mathrm{CH}_{3}\right)$. The $\mathrm{O}-\mathrm{H}$ bending vibration at $1295-1285 \mathrm{~cm}^{-1}$ found in all extraction methods. The $\mathrm{C}-\mathrm{O}$ stretching vibration occurred at range $1237-1235 \mathrm{~cm}^{-1}$ and $1196-192 \mathrm{~cm}^{-1}$ were only found in all extraction methods

A peak at $1121-1117 \mathrm{~cm}^{-1}$ was seen only in $95 \%$ of ethanol due to $\mathrm{C}-\mathrm{O}$ stretching vibration of saturated secondary alcohol. The presence of peak at 1034-1032 $\mathrm{cm}^{-1}$ was related to C-O streching vibration of primary alcohol, which was found in all extraction methods. However, $70 \%$ ethanol by maceration and sonication showed strong and intense absorption as compared to $95 \%$ ethanol and both in soxhlet method. Peak at $883-880 \mathrm{~cm}^{-1}$ was presented in all extraction methods and attributed to aromatic $\mathrm{C}-\mathrm{H}$ out-of-plane bending vibration of $1,3-$ disubstitution (meta) while peak at $826-813 \mathrm{~cm}^{-1}$ was contributed to aromatic C-H out-of-plane bending vibration of 1,4- disubstitution (para). This peak was degraded after propolis was extracted more than 60 minutes by sonication. Peaks in the range of $773-768 \mathrm{~cm}^{-1}$ and $745-$ $743 \mathrm{~cm}^{-1}$ were attributed to the monosubstituion (phenyl) or 1,2disubstitution (ortho) and occurred in all extraction.

In addition, peak at $719-718 \mathrm{~cm}^{-1}$ was assigned to aromatic $\mathrm{C}-\mathrm{H}$ out-of-plane bending vibration was only presented in $95 \%$ ethanol in all extraction methods. Peaks in the ranges of $634-630 \mathrm{~cm}^{-1}, 590-586$ $\mathrm{cm}^{-1}$ and $565-550 \mathrm{~cm}^{-1}$ were attributed to $\mathrm{O}-\mathrm{H}$ out-of-plane bending vibration of alcohol. These peaks presence in all extraction methods. The summary of the FTIR assignments was illustrated in Table 1. Typically, the stretching mode has higher energy as compared to bending mode. Stretching mode could be divided into two; symetrical and assymetrical, which the assymetrical usually has higher energy.

The energy of stretching mode was decreased as the mass of atom was increased such as the $\mathrm{C}-\mathrm{H}$ stretching vibration has higher energy compared to $\mathrm{C}-\mathrm{C}$ stretching vibration. Furthermore, the stronger the bond $(\mathrm{C} \equiv \mathrm{C}>\mathrm{C}=\mathrm{C}>\mathrm{C}-\mathrm{C})$ the higher the energy to vibrate. The higher energy, the higher wavenumber. Overall, the assignment of peaks from FTIR spectra of propolis extracts by three different methods of extraction for both $70 \%$ and $95 \%$ ethanol was found that, the extraction methods and their durations played significant roles in extracting different types of compounds which resulted in giving out different vibrationals of functional groups at different periods of time.

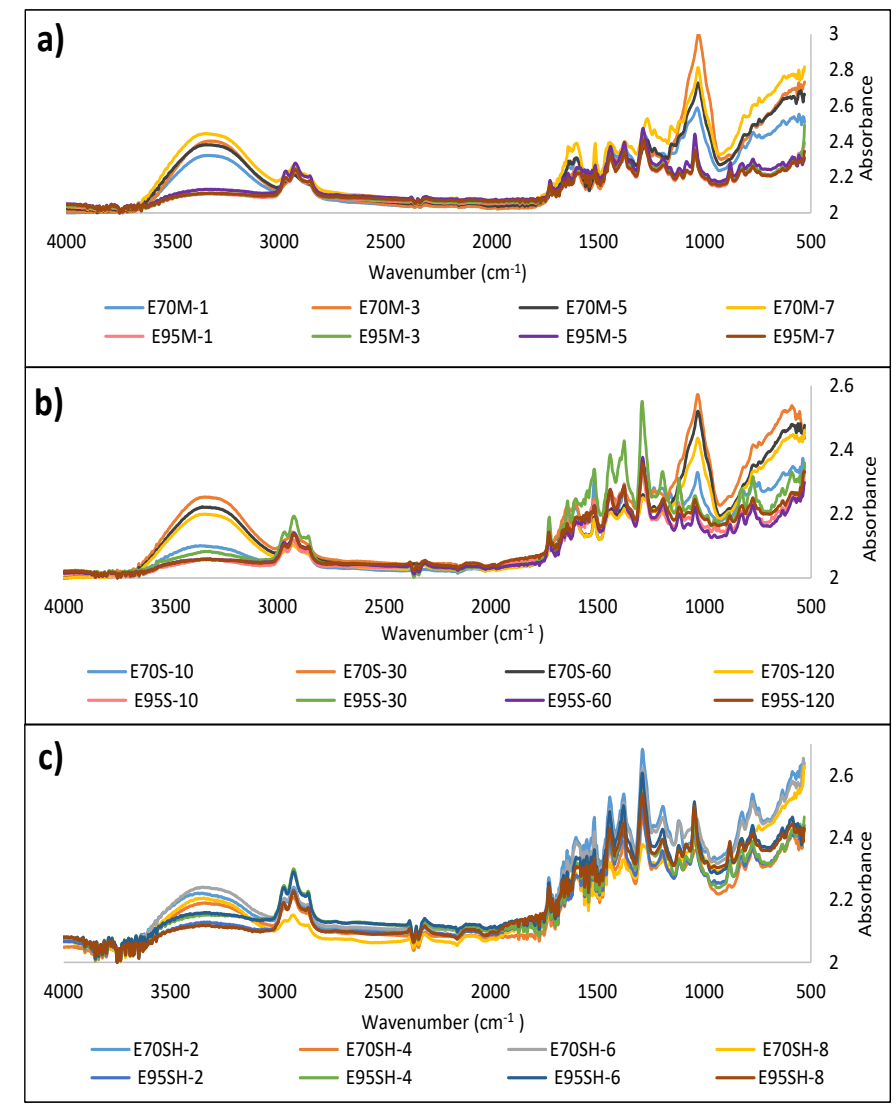

Fig. 1 FTIR spectra of propolis extraction of stingless bee by different extraction methods (a) maceration, (b) sonication and (c) soxhlet. 
Md Zin et al. / Malaysian Journal of Fundamental and Applied Sciences

Table 1 Summary of the FTIR assignments.

\begin{tabular}{|c|c|}
\hline Peak ranges & Functional groups \\
\hline $3500-3200$ & Intermolecular hydrogen bonding (O-H stretching vibrations) \\
\hline 2968 & Asymmetrical stretching (VasCH3) of methyl group \\
\hline \multirow{2}{*}{$\frac{2926}{2855}$} & Asymmetrical stretching (VasCH2) of methylene group \\
\hline & Symmetrical streching of ( $\mathrm{VsCH} 2)$ of methylene group \\
\hline $2382-2350$ & False positive \\
\hline $1728-1726$ & $\mathrm{C}=\mathrm{O}$ streching vibration of aliphatic aldehydes \\
\hline $1715-1711$ & Normal $\mathrm{C}=\mathrm{O}$ streching vibration of saturated aliphatic ketone \\
\hline $1697-1692$ & $\mathrm{C}=\mathrm{O}$ stretching vibration of ab unsaturated and aryl cnjugated carboxylic acid \\
\hline $1666-1665$ & $\mathrm{C}=\mathrm{C}$ streching vibration of disubstituted trans alkene, tri- and tetraalkyl-substituted alkenes \\
\hline 1659 & $\mathrm{C}=\mathrm{C}$ streching vibration of cis- alkene \\
\hline $1644-1641$ & $\mathrm{C}=\mathrm{C}$ streching vibration of vinyl group \\
\hline 1636-1632 & $\mathrm{C}=\mathrm{C}$ streching vibration \\
\hline $1604-1600$ & Conjugated $\mathrm{C}=\mathrm{C}$ of streching vibration \\
\hline $1587-1582$ & $\mathrm{C}=\mathrm{C}-\mathrm{C}$ aromatic ring streching \\
\hline $1574-1572$ & $\mathrm{C}=\mathrm{C}$ streching vibration \\
\hline 1564 & $\mathrm{C}=\mathrm{C}$ streching vibration \\
\hline $1557-1553$ & $\mathrm{C}=\mathrm{C}$ streching vibration \\
\hline $1549-1547$ & $\mathrm{C}=\mathrm{C}$ streching vibration \\
\hline $1517-1515$ & $\mathrm{C}=\mathrm{C}-\mathrm{C}$ aromatic streching vibration \\
\hline $1439-1433$ & $\mathrm{C}-\mathrm{H}$ asymmetrical bending vibration $\mathrm{CH} 3$ \\
\hline $1377-1374$ & $\mathrm{C}-\mathrm{H}$ symmetrical bending vibration $\mathrm{CH} 3$ \\
\hline $1295-1285$ & $\mathrm{O}-\mathrm{H}$ bending vibration \\
\hline $1237-1235$ & phenols C-O streching \\
\hline 1196-1192 & Phenol, C-O streching vibration \\
\hline $1121-1117$ & C-O streching saturated secondary alcohol \\
\hline $1034-1032$ & C-O streching primary alcohol \\
\hline $883-880$ & 1,3- disubstitution (meta) of aromatic C-H out-of-plane bending vibration \\
\hline $826-824$ & 1,4- disubstitution (para) of aromatic C-H out-of-plane bending vibration \\
\hline $773-768$ & 12- disubstitution (ortho) of aromatic $\mathrm{C}-\mathrm{H}$ out-of-nlane hending vibration \\
\hline $745-743$ & 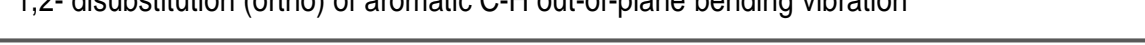 \\
\hline $719-718$ & Alcohol, O-H out-of-plane bend of aromatic C-H out-of-plane bending vibration \\
\hline $634-630$ & Alcohol, O-H out-of-plane bending vibration \\
\hline $590-586$ & Alcohol, O-H out-of-plane bending vibration \\
\hline
\end{tabular}

\section{Chemometric analysis of FTIR fingerprint}

FTIR spectrum revealed certain functional groups based on $\mathrm{x}$-axis (wavelength) and $y$-axis (transmittance) that coming from the vibration of molecules in the propolis samples. It formed a complex and overlapping spectrum in each extraction methods. Hence, chemometric analysis is important to differentiate each of them. The Principal Component analysis (PCA) and Hierarchical Cluster Analysis (HCA) were employed in chemometric analysis. Based on Fig. 2, the PCA of FTIR data for different extraction methods of stingless bee's propolis revealed the variability of PC1 and PC2 after varimax rotation (VFs) was $87.84 \%$. The result from factor score showed that maceration (70M-1), sonication (70S-10, 70S-30, 70S-60, $70 \mathrm{~S}-120$ and 95S-30) and soxhlet (all samples) were classified into VF1. Meanwhile maceration (70M-3, 70M-5, 70M-7, 95M-1, 95M-3, 95M-5 and 95M-7) and sonication (95S-10, 95S-60 and 95S-120) were classified into VF1. There were fourteen variables that classified the extraction methods of propolis into $\mathrm{PC} 1$ and nine variables in $\mathrm{PC} 2$ as shown in Table 2. The loading factor (Table 2) showed PCA's variation in propolis by different extraction methods was classified based on specific functional groups arise from the peaks. From PCA score plot, the propolis extraction methods were classified into three groups which were group 1 (all samples by maceration in $70 \%$ ethanol and sonication in $70 \%$ ethanol for 30,60 and 120 minutes), group 2 (all soxhlet methods) and group 3 (all samples by maceration in $95 \%$ ethanol and all sample by sonication in $95 \%$ ethanol and $70 \%$ ethanol for 10 minutes extraction).

The results of these three groups from PCA score plot (Fig 2) were related to HCA of dendogram results (Fig 3). The extraction methods that classified in group 1 were distributed in Cluster I, while group 2 and 3 were classified into cluster II and III. Samples were clasified within cluster and found to be similar to each other, meanwhile, samples that classified into different clusters were different with each other in some senses. The dot lines in dendograms indicated that the automatic truncation was cut off to determine the significant clusters. The HCA revealed the extraction methods of propolis were classified based on percentages of ethanol and peak intensities and different fingerprint region. The propolis extracted with $70 \%$ of ethanol was classified into cluster I and III, while propolis extracted with $95 \%$ of ethanol classified into cluster II. Cluster I was classified based on $\mathrm{C}=\mathrm{C}$ stretching vibration and have highest intensities spectra of $\mathrm{C}-\mathrm{O}$ stretching of primary alcohol. Cluster II was characterized based on lowest intensities spectra of $\mathrm{O}$ $\mathrm{H}$ intermolecular hydrogen bonding stretching vibration, $\mathrm{C}-\mathrm{O}$ stretching vibration and aromatic $\mathrm{C}-\mathrm{H}$ out-of-plane bending vibration. Cluster III was classified based on highest intensities spectra of $\mathrm{O}-\mathrm{H}$ bending vibration and C-O stretching saturated secondary alcohol. 


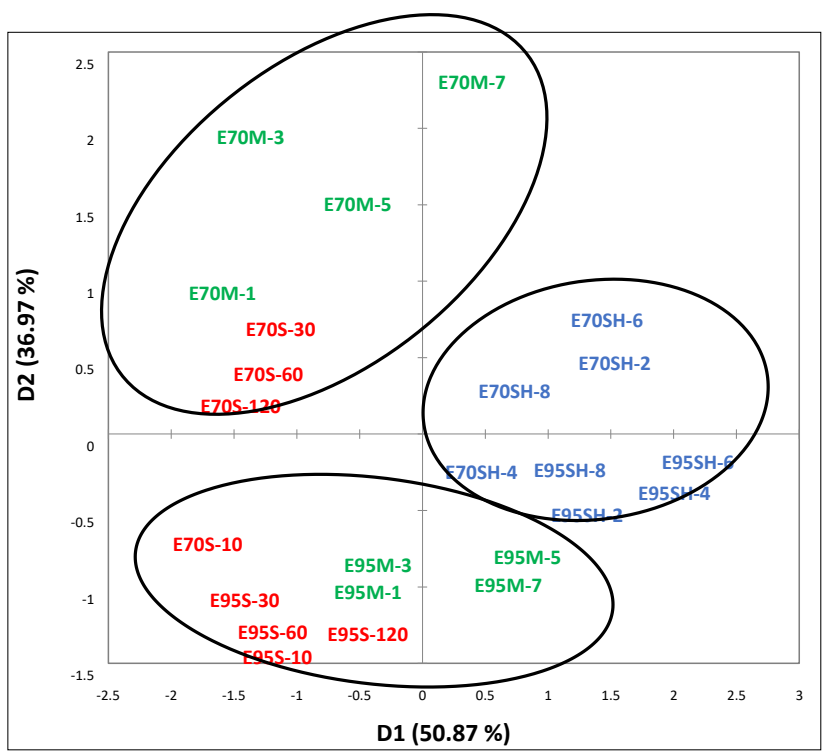

Fig. 2 PCA score plots of propolis extraction of stingless bee by different extraction methods (a) maceration, (b) sonication and (c) soxhlet.

Table 2 Summary of the FTIR assignment based on varimax factors.

\begin{tabular}{|c|c|c|}
\hline VFs & Peaks range & $\begin{array}{l}\text { Assignment for vibrational of functional groups for } \\
\text { specific peaks }\end{array}$ \\
\hline \multirow{14}{*}{ VF1 } & 2855 & Symmetrical stretching of $\left(\mathrm{VsCH}_{2}\right)$ of methylene group \\
\hline & $2382-2350$ & $\begin{array}{l}\text { False positive (due to due to atmospheric intrusion such as } \\
\text { humidity (Chalmers, 2006)) }\end{array}$ \\
\hline & $1728-1726$ & $\mathrm{C}=\mathrm{O}$ stretching vibration of aliphatic aldehydes \\
\hline & $1697-1692$ & $\begin{array}{c}\mathrm{C}=\mathrm{O} \text { stretching vibration of unsaturated and aryl conjugated } \\
\text { carboxylic acid }\end{array}$ \\
\hline & $1666-1665$ & $\begin{array}{c}\mathrm{C}=\mathrm{C} \text { stretching vibration of disubstituted trans alkene, tri- and } \\
\text { tetraalkyl-substituted alkenes }\end{array}$ \\
\hline & 1659 & $\mathrm{C}=\mathrm{C}$ stretching vibration of cis- alkene \\
\hline & $1587-1582$ & $\mathrm{C}=\mathrm{C}-\mathrm{C}$ aromatic ring stretching \\
\hline & $1574-1572$ & $\mathrm{C}=\mathrm{C}$ stretching vibration \\
\hline & 1564 & $\mathrm{C}=\mathrm{C}$ stretching vibration \\
\hline & $1557-1553$ & $\mathrm{C}=\mathrm{C}$ stretching vibration \\
\hline & $1549-1547$ & $\mathrm{C}=\mathrm{C}$ stretching vibration \\
\hline & $1439-1433$ & $\mathrm{C}-\mathrm{H}$ asymmetrical bending vibration $\mathrm{CH}_{3}$ \\
\hline & $1295-1285$ & $\mathrm{O}-\mathrm{H}$ bending vibration \\
\hline & $1196-1192$ & C-O stretching vibration \\
\hline \multirow{9}{*}{ VF2 } & $3500-3200$ & Intermolecular hydrogen bonding ( $\mathrm{O}-\mathrm{H}$ stretching vibrations) \\
\hline & $1636-1632$ & $\mathrm{C}=\mathrm{C}$ stretching vibration \\
\hline & $1121-1117$ & C-O stretching saturated secondary alcohol \\
\hline & $1034-1032$ & C-O stretching primary alcohol \\
\hline & $883-880$ & \multirow{5}{*}{ Aromatic $\mathrm{C}-\mathrm{H}$ out-of-plane bending vibration } \\
\hline & $826-824$ & \\
\hline & $773-768$ & \\
\hline & $745-743$ & \\
\hline & $719-718$ & \\
\hline
\end{tabular}

\section{CONCLUSION}

From this study, different extraction methods played important role in determination of chemical composition in propolis of stingless bee. FTIR coupled with chemometric analysis showed classification of different extraction methods of propolis from PCA and HCA based on vibration of functional groups presented in the samples. Hence, PCA and HCA were considered to be very popular tool to summarize a dataset into a few factors which highlighted the most important information to optimize method of extractions.

\section{ACKNOWLEDGEMENT}

This study work was funded by Fundamental Research Grant Scheme (FRGS) with project code FRGS/1/2017/WAB01/UNISZA/02/01

\section{REFERENCES}

Ami, D., Mereghetti, P., Doglia, S., M. 2012. Multivariate analysis for fourier transform infrared spectra of complex biological systems and processes. Intech Open, 10, 190-220.

Araujo, K. S. D. S., Joaquim, D. S. J., Marcello, O. S., Fernanda, D. B., Ilsamar, M. S., Robson, B., Tarso, D. S. A., Sergio, D. A., Sandra, M. B. M. 2016. Physicochemical properties and antioxidant capacity of propolis of stingless bees (Meliponinae) and Apis from two Regions of Tocantins, Brazil. Acta Amazonica. 46(1), 61-68.

Azemin, A., Md-Zin, N. B., Mohd-Rodi, M. M., Kim- Chee, A. S., Zakaria, A. J., Mohd, K. S. 2017. Application of metabolite profilling and antioxidant activity in assesing the quality of the processed and unprocessed stingless bee's propolis. Journal of Fundamental and Applied Science. 9(2S), 637 660.

Azwanida, N. N. 2015. A review on the extraction methods use in medicinal plants, principle, strength and limitation. Medicinal and Aromatic Plants, 4(196), 2167-0412.

Bankova, V., Popova, M., Trusheva, B. 2014. Propolis volatile compounds: chemical diversity and biological activity: a review. Chemistry Central Journal, 8(28), 1-8.

Chalmers, J. M. 2006. Mid-infrared spectroscopy: Anomalies, artifacts and common errors. Handbook of Vibrational Spectroscopy. Wiley Online Library, 2327-2347.

Cleidiane, S., Anaclara, P., Matheus, A. C., Vanderlei, A. L.,Tatiane, L. C. O. 2018. Determination of total phenolic compounds and antioxidant activity of ethanolic extracts of propolis using ATR-FT-IR spectroscopy and chemometrics. Food Analytical Methods, 11(7). 2013-2021.

Gad, H, A., El-Ahmady, S. H., Abou-Shoer, M. I., Al-Azizi, M. M. 2013. Application of chemometrics in authentication of herbal medicines: A review. Phytochemcal Analytical, 24, 1-24.

Herve, A., Lynne, J. W. 2010. Principal component analysis. John Wiley \& Sons. 2, Wiley Online Library, 433-459.

Irene, M., Dewi, F. S., Ellyza, H., Zainal A. M. 2012 . Optimization and comparative study of different extraction methods of biologically active components of Indonesian propolis Trigona spp. Journal of Natural Products, 5, 233-242.

Jolliffe, I. T. 2002. Principal Component Analysis. Springer. New York, 2, 32 37.

Khacha-Ananda, S., Tragoolpua, K., Chantawannakul, P., Tragoolpua, Y. 2013. Antioxidant and anti-cancer cell proliferation activity of propolis extracts from two extraction methods. Asian Pacific Journal of Cancer Prevention, 14(11), 6991-6995.

Kothai S., Jayanthi B. 2015. Environmental impact on stingless bee propolis (Tetragonula iridipennis) reared from two different regions of Tamilnadu - a comparative study. International Journal of ChemTech Research, 7(7), 3081-3088.

Magdalena, W., Izabela, R., Kinga, S., Patrycja, K., Bartłomiej, M. 2016. Propolis and organosilanes in wood protection. Part I: FTIR analysis and biological tests. Annals of Warsaw University of Life Sciences - SGGW Forestry and Wood Technology, 91(2015), 218-224.

Milena, P., Efstathia, G., Krystyna, S. K. G., Jaroslaw, W., Vassya, B., Haralabos, K., Gregory, S., K., Beata, A., Ioanna, C. 2017. Characterization and biological evaluation of propolis from Poland. Molecules, 22, 2-13.

Ming, J., J., Shane, R., S., Cheng, C. G., Yen, L. H., Kun, S. H. 2009. Optimization analysis of the experimental parameters on the extraction process of propolis. Proceedings of the International MultiConference of Engineers and Computer Scientists 2009 Vol II, IMECS 2009, March 18 20, Hong Kong.

Mohamad-Asri, M. N., Mat-Desa, W. N. S., Ismail, D. 2018. Combined principal component analysis (PCA) and hierarchical cluster analysis (HCA): An efficient chemometric approach in aged gel inks discrimination. Australian Journal of Forensic Sciences, 1-22.

Niken, P., Ritonga, H., Uslinawaty, Z. 2014. Properties and flavonoids content in propolis of some extraction method of raw propolis. International Journal of Pharmacy and Pharmaceutical Sciences, 6(6), 975-1491.

Prashant, T., Bimlesh, K., Mandeep, K., Gurpreer, K., Harleen, K. 2011. Phytochemical screening and extraction: $\mathrm{A}$ review. Internationale Pharmaceutica Sciencia. 1(1), 98-106.

Renata, N. O., Maurício, C. M., Fernando, C. S. O., Thayse, M. P., Brid, Q., Rossana, M. M. T., Garrett, B. M. 2016. FTIR analysis and quantification of 
phenols and flavonoids of five commercially available plants extracts used in wound healing. Revista Materia, 21(3), 767-779.

Ricardo, S., Fatima., Cristina, A. A. 2015. Propolis : A complex natural product with a phlethora of biological activities that can be explored for drug development. Evidence-based Complementary and Alternative Medicine, 2015, 1-29.

Rohman, A., Salamah, N. 2018. The employment of spectroscopic techniques coupled with chemometrics for authentication analysis of hala pharmaceuticals. Journal of Applied Pharmaceutical Science, 8(10), 63-68.

Tian, Y., Xu, Z., Zheng, B., Lo, Y. M. 2013. Optimization of ultrasonicassisted extraction of pomegranate (Punica granatum L.) seed oil Ultrasonics Sonochemistry, 20, 202-208. 